\title{
Is procalcitonin a good marker for Acinetobacter infections?
}

\author{
Đinuhal Özer Şimşek \\ Division of Intensive Care, Department of Internal Medicine, Erciyes University, Kayseri, Turkey
}

Cite this article as: Özer Şimşek Z. Is procalcitonin a good marker for Acinetobacter infections? Anatolian Curr Med J 2021; 3(1); 1-4.

\begin{abstract}
Aim: Culture is the most important method in the diagnosis of infectious diseases, but diagnosis may be delayed with culture. Therefore, pro-inflammatory markers are used for early diagnosis of infections. Procalcitonin, a precursor of calcitonin, takes part in the systemic reactions caused by circulating endotoxins and inflammatory cytokines. The aim of this study is to investigate the utility of procalcitonin in the early diagnosis and treatment follow-up of Acinetobacter baumannii infections.

Material and Method: A total of 96 patients, 63 with A. baumannii and 33 with systemic infections caused by Klebsiella spp., Escherichia coli, Enterobacter spp., Pseudomonas spp, Stenotrophomonas maltophilia, Staphylococcus aureus were included in the study. The cultured areas were endotracheal aspirate, sputum, bronchoalveolar lavage and blood culture. Leukocyte count, C-reactive protein and procalcitonin were used as inflammation markers.

Results: The procalcitonin levels in the group with infection due to A. baumannii were found to be significantly lower than the other group $(\mathrm{p}<0.05)$. There was no statistically significant difference between the two groups in terms of $\mathrm{C}$-reactive protein and leukocyte levels.
\end{abstract}

Conclusion: Unlike other bacterial infections, procalcitonin may not increase in the early stages of A. baumannii infections. This situationshould be considered in the early diagnosis of systemic infections.

Keywords: Acinetobacter, procalcitonin, C-reactive protein, sepsis

\section{INTRODUCTION}

Microbiological sampling is the gold standard for the diagnosis of sepsis; however, identification requires time to result, and empirical antibiotics are needed to start for reducing mortality until obtained culture results. Some biomarkers are used to give an idea to start suitable empiric antibiotics while awaiting the culture results (1). White blood cell (WBC), procalcitonin (PCT) and C-reactive protein (CRP) are commonly used in the diagnosis of sepsis in the intensive care unit (ICU) (2). Procalcitonin is the precursor molecule of calcitonin and is produced mainly by the thyroid gland. Inflammation and tissue damage increases procalcitonin synthesis (1). Procalcitonin can be detected in the blood 2-4 hour after the onset of infections. Procalcitonin levels reach peak levels in serum within 6 to 24 hours and can be detected until seven days (3). Its production increases in response to a pro-inflammatory stimulus, especially of bacterial origin. While normal basal levels in most adults are $<0.01$ $\mathrm{ng} / \mathrm{mL}$, procalcitonin levels can rapidly increase by 400 fold ( $>4 \mathrm{ng} / \mathrm{mL}$ ) when stimulated by an endotoxin (4).

\section{MATERIAL AND METHOD}

Ethics committee approval was obtained from Erciyes University by the decision number of 2018/617 on 05.12.2018. All procedures were performed adhered to the ethical rules and the Helsinki Declaration of Principles.

\section{Study design}

The study was performed in the tertiary intensive care unit (ICU) of internal medicine in a university hospital. The ICU has a capacity of 16 beds. The data were obtained from the medical and laboratory records between January 2014 and December 2018 retrospectively. Sixty-three patients with Acinetobacter baumannii in any culture were included in the study group, and 33 patients with infections due to other bacterial agents (Klebsiella spp., Escherichia coli, Enterobacter spp., Pseudomonas spp, Stenotrophomonas maltophilia, Staphylococcus aureus) were included as the control group. Leukocyte, CRP and PCT count were used as inflammation markers. PCT and CRP levels were recorded in before 48 hours from culture, 
culture date, and daily white blood cell (WBC) count too. Patients who were previously receiving specific treatment for A.baumannii and patients with cancer, autoimmune diseases, trauma and under 18 years of age were excluded.

Procalcitonin, CRP are taken routinely at 48-hour intervals and $\mathrm{WBC}$ is evaluated daily in ICU. First samples of PCT, CRP and WBC were taken 48 hours before culture, second ones were taken the day of culture and third ones were obtained after 48 hours from culture. We used these data as a retrospectively. Cultures were taken in cases of deterioration in the patient's clinic, increasing body temperature, mechanical ventilatory support and/or inflammatory markers such as CRP, PCT, WBC $(5,6)$. Serum procalcitonin was measured by the immune-luminometric method in the biochemistry laboratory. CRP was measured by nephelometry immunoassay, and white blood cell count was performed on K3EDTA-treated blood, using an automated Coulter JT hematology analyzer. An immune-luminometric assay and CRP concentrations obtained PCT levels by use of a nephelometric assay.

\section{Statistical Analysis}

Values were indicated as mean \pm standart error mean (SEM). Categorical data were analyzed by chi-square and nonparametric fisher exact test, numerical data by student-t-test, and nonparametric by the MannWhitney $\mathrm{U}$ test. A p-value $<0.05$ was considered significant. Spearman's rank correlation coefficient tested for associations of the biomarkers.

\section{RESULTS}

A total of 96 patients (63 patients in A. baumannii group and 33 patients in the non-acinetobacter group) were included in the study. Demographic data of both groups were summarized in Table 1 . In the A. baumannii group, PCT values were measured before 48 hours from culture, day of culture and after 48 hours from culture $1.7 \pm 3.2,1.6 \pm 2.5$ and $8.1 \pm 21.7 \mathrm{ng} / \mathrm{mL}$, respectively, and in the non-acinetobacter group, same parameters were measured at the same time $7.6 \pm 9.7,3.6 \pm 3.7$ and $9.4 \pm 16.5 \mathrm{ng} / \mathrm{mL}$ respectively. In terms of PCT value in three times between two groups, there was a statistically significant difference $(\mathrm{p}=0.01,0.04$ and 0.01 respectively). The non-acinetobacter group had higher PCT levels than A. baumannii group. Other parameters $\mathrm{CRP}$ and WBC were examined before 48 hours from culture and day of culture; there was no statistically significant difference between two groups among these parameters ( $p>0.05)$ (Table 2). In A. baumannii group before 48 hours culture, $41.8 \%$ of patients had PCT levels lower than $0.5 \mathrm{ng} / \mathrm{mL}$, whereas during culture day $46.0 \%$ of patients had PCT levels lower than 0.5 $\mathrm{ng} / \mathrm{mL}$. In non-acinetobacter group before 48 hours culture, $28 \%$ of patients had PCT levels lower than 0.5 $\mathrm{ng} / \mathrm{mL}$, whereas, during culture day, $6 \%$ of patients had PCT levels lower than $0.5 \mathrm{ng} / \mathrm{mL}(\mathrm{p}=0.03)$. There was a positive correlation in culture day between PCT and CRP levels in non-acinetobacter group ( $\mathrm{p}=0.02 \mathrm{r}: 0.39)$ while, there wasn't any correlation in the A. baumannii group in terms of these parameters.

\begin{tabular}{|lccc|}
\hline Table 1. Demographic features of the patients \\
\hline Characteristics & $\begin{array}{c}\text { Acinetobacter } \\
\text { group }\end{array}$ & $\begin{array}{c}\text { Control } \\
\text { group }\end{array}$ & p \\
\hline Subjects (n) & 63 & 33 & \\
Sex (male/female) & $\begin{array}{c}39 \\
(62 \%) / 24 \\
(38 \%)\end{array}$ & $\begin{array}{c}(54.5 \%) / 15 \\
(45.5 \%)\end{array}$ & $0.06 / 0.12$ \\
Age (years) & $57.9 \pm 19.8$ & $62.2 \pm 17$ & 0.33 \\
Comorbidity & $14(22 \%)$ & $4(12.1 \%)$ & 0.62 \\
$\begin{array}{l}\text { None (or N/A), n (\%) } \\
\text { Hypertension }\end{array}$ & $19(30 \%)$ & $17(51.5 \%)$ & 0.35 \\
$\begin{array}{l}\text { Coronary artery disease } \\
\text { Congestive heart failure }\end{array}$ & $17(26.9 \%)$ & $12(36.3 \%)$ & 0.42 \\
$\begin{array}{l}\text { Diabetes mellitus } \\
\text { Chronic obstructive } \\
\text { pulmonary disease }\end{array}$ & $15(23.7 \%)$ & $4(12.1 \%)$ & 0.27 \\
$\begin{array}{l}\text { Duration of stay in } \\
\text { intensive care (days) }\end{array}$ & $9(14.2 \%)$ & $8(24.2 \%)$ & 0.06 \\
$\begin{array}{l}\text { Mechanical ventilation } \\
\text { requirement }\end{array}$ & $24.9 \pm 18.5$ & $18.9 \pm 10.4$ & 0.31 \\
$\begin{array}{l}\text { Mortality (\%) } \\
\text { Culture specimen (n) }\end{array}$ & $43(95.2 \%)$ & $29(87.8 \%)$ & 0.19 \\
$\begin{array}{l}\text { ETA*, bronchial lavage } \\
\text { Peripheral blood }\end{array}$ & $41(65 \%)$ & $11(33.3 \%)$ & 0.05 \\
Catheter blood & $22(34.9 \%)$ & $12(36.3 \%)$ & 0.61 \\
\hline${ }^{*}$ Endotracheal aspiration & $14(22 \%)$ & $10(30.3 \%)$ & 0.19 \\
\hline
\end{tabular}

Table 2. PCT, CRP, WBC levels of the groups

\begin{tabular}{|lccc|} 
& $\begin{array}{c}\text { Acinetobacter } \\
\text { group }\end{array}$ & $\begin{array}{c}\text { Non-acinetobacter } \\
\text { group }\end{array}$ & $\mathbf{p}$ \\
\hline PCTpre48 & $1.6 \pm 2.5$ & $3.6 \pm 3.7$ & 0.04 \\
PCTx & $1.7 \pm 3.2$ & $7.6 \pm 9.7$ & 0.01 \\
PCTpost48 & $8.1 \pm 21.7$ & $9.4 \pm 16.5$ & 0.01 \\
Median values & & & \\
WBCpre48 & $9.6(0.25-45.5)$ & $11.1(3.20-32.7)$ & $\mathrm{P}>0.05$ \\
WBCpre24 & $10.5(0.16-32.2)$ & $11.1(3-29.8)$ & $\mathrm{P}>0.05$ \\
WBCx & $10.2(0.34-27.6)$ & $10.3(1.24-30.9)$ & $\mathrm{p}>0.05$ \\
CRPpre48 & $94.5(8-323)$ & $99.7(2.7-386)$ & $\mathrm{p}>0.05$ \\
CRPx & $93.7(4.5-400)$ & $122(13.4-400)$ & $\mathrm{p}>0.05$ \\
PCTpre48 & $0.75(0.05-12.4)$ & $2.09(0.1-11.57)$ & $\mathrm{p}>0.05$ \\
PCTx & $0.54(0.04-20.1)$ & $3.07(0.05-32.7)$ & $\mathrm{p}>0.05$ \\
\hline WBC & & &
\end{tabular}

WBC: White blood cell, $\times 10^{3} / \mu \mathrm{L} \quad \mathrm{CRP}=\mathrm{C}$-reactive protein $(0-5 \mathrm{mg} / \mathrm{L})$, PCT: Procalcitonin $(0-0.5 \mathrm{ng} / \mathrm{mL})$ Pre 48 : 48 hours before culture day, $\mathrm{x}$ : culture day, post 48 : 48 hours after culture day. Data are presented as mean \pm SD and median (min-max).

Antibiotic susceptibility pattern of all patients in $A$. baumannii group showed multidrug resistance including carbapenems. 
When the groups were compared in terms of bacteremia as considered culture results and septic shock, less bacteremia and more septic shock were observed in $A$. baumannii group (A. baumannii group, 57.1\%, 65.0\%; non-acinetobacter group $66.6 \%, 51.5 \%$ respectively.)

The most common comorbid conditions in both groups were diabetes mellitus, hypertension and coronary artery disease. There was no significant difference between the groups in terms of comorbid diseases ( $p>0.05)$ (Table 1).

According to the initiation of colistin (polymyxin E), patients with $A$. baumannii growing in their culture were divided into four groups. Group 1 was not administered any colistin (n:18), group 2 colistin was administered before 48-hour from culture (n:9), the third one was administered culture day, and up to 48-hour after culture $(\mathrm{n}: 15)$ and the last group was administered after 48hour from culture (n:21). There wasn't any statistically significant difference among groups in terms of PCT levels before 48 -hour culture and culture day $(\mathrm{p}>0.05)$

\section{DISCUSSION}

Procalcitonin, which is one of the proinflammatory markers expected to increase in bacterial infections (1). This presented study revealed that there was a less expected increase in A. baumannii infections compared to other agents. PCT was not a predictive marker for a new and resistant infection in patients with clinically and radiologically progressive in ICU according to this study findings. In a consensus report, clinical, radiological findings were reported as more critical than pro-inflammatory markers (1). To our knowledge, there wasn't any study about procalcitonin levels in Acinetobacter infections, in the literature.

In the presence of bacterial infection, PCT is produced in by the macrophage and monocytic cells throughout the body, especially in the liver, lung, and intestine (7). Its diagnostic and predictive value decreases in patients with severe sepsis (8). In a study, patients with procalcitonin levels below 0.25 were less likely to have an infection and recommended antibiotic discontinuation, Similarly, if procalcitonin level is between 0.25 and $0.5 \mathrm{mg} / \mathrm{L}$, bacterial infection was unlikely while in this study, $25 \%$ of patients with A. baumannii infection had a lower PCT level below $0.25 \mathrm{mg} / \mathrm{l}$, additional $20 \%$ of patients with A. baumannii buster had PCT levels between $0.25-0.5 \mathrm{mg} / \mathrm{l}$ (9). Choe et al. (10) demonstrated that the PCT was tending to increase in bacteremia and initial septic shock, while PCT levels were lower in local infections such as pneumonia. PCT concentrations should be interpreted differently depending on the source of infection. In a study showed that significantly higher PCT levels were found in patients with Escherichia, Klebsiella and
Pseudomonas in blood cultures (11). The presented study showed that low PCT levels in A. baumannii group might be related that more local infections and septic shock were detected in that group.

Procalcitonin is used as a predictor marker for starting antibiotics in first studies (12). Some studies suggested that PCT is a useful marker for early sepsis while others did not offer as a criterion for starting antibiotics in terms of ventilator associated pneumonia $(13,14)$. Also PCT for reduced antibiotic exposure in ventilator-associated pneumonia a randomised study (15). In a similar study, antibiotics were discontinued according to PCT levels, and they revealed that significantly lower antibiotic consumption and significantly lower 28-day and 1-year mortality rates (16). This study suggested that PCT is not suitable to start or stop antibiotics in patients with A. baumannii infections due to lower levels of PCT and low, an increasing trend. Furthermore, in the A. baumannii group, there was no significant difference in PCT levels between patients who had not started colistin, and who had started colistin before, during and after culture. For these reasons, the PCT may be not a useful marker for A. baumannii infections.

This study has some limitations such as relatively low number of patients and retrospective study. If the study was prospective, PCT levels could be measured more often, perhaps a specific cut-off value could be determined and factors affecting PCT would be better recorded such as antibiotics, drugs, or source of bacterial growth. If the culture results were more detailed, the agent specific PCT cut-off value might have been determined.

\section{CONCLUSION}

The fact that PCT levels do not show the expected increase in severe infections caused by A. baumannii, as in other agents, suggests that PCT is not a useful marker for $A$. baumannii infections. Since there was no significant difference between PCT levels in A. baumannii infections with and without empirical antibiotics, the predictive value of antibiotic initiation and discontinuation was poor. Further studies are needed for the importance and predictive value of PCT.

\section{ETHICAL DECLARATIONS}

Ethics Committee Approval: The study was carried out with the permission of local Ethics Committee of Erciyes University (Permission granted: 05.12.2018, Decision no: 2018/617).

Informed Consent: Because the study was designed retrospectively, no written informed consent form was obtained from patients. 
Referee Evaluation Process: Externally peer-reviewed. Conflict of Interest Statement: The authors have no conflicts of interest to declare.

Financial Disclosure: The authors declared that this study has received no financial support.

Author Contributions: All of the authors declare that they have all participated in the design, execution, and analysis of the paper, and that they have approved the final version.

Acknowledgment: Associate Professor Kursat Gündoğan

\section{REFERENCES}

1. Peters RP, van Agtmael MA, Danner SA, Savelkoul PH, Vandenbroucke-Grauls CM. New developments in the diagnosis of bloodstream infections. Lancet Infect Dis 2004; 4: 751-60.

2. Garnacho-Montero J, Huici-Moreno MJ, Gutierrez-Pizarraya A, et al. Prognostic and diagnostic value of eosinopenia, C-reactive protein, procalcitonin, and circulating cell-free DNA in critically ill patients admitted with suspicion of sepsis. Crit Care 2014; 18 : R116.

3. Gilbert DN. Use of plasma procalcitonin levels as an adjunct to clinical microbiology. J Clin Microbiol 2010; 48: 2325-9.

4. Dandona P, Nix D, Wilson MF, et al. Procalcitonin increase after endotoxin injection in normal subjects. J Clin Endocrinol Metab 1994; 79: 1605-8.

5. Fabre V, Sharara SL, Salinas AB, Carroll KC, Desai S, Cosgrove SE. Does this patient need blood cultures? a scoping review of indications for blood cultures in adult nonneutropenic inpatients. Clin Infect Dis 2020; 71: 1339-47.

6. Kalil AC, Metersky ML, Klompas M, et al. Management of adults with hospital-acquired and ventilator-associated pneumonia: 2016 clinical practice guidelines by the Infectious Diseases Society of America and the American Thoracic Society. Clin Infect Dis 2016; 63: e61-e111.

7. Moya F, Nieto A, JL RC. Calcitonin biosynthesis:evidence for a precursor. Eur J Biochem 1975; 55: 407-13.

8. Meisner M. Update on procalcitonin measurements. Ann Lab Med 2014; 34: 263-73.

9. Hamade B, Huang DT. Procalcitonin: where are we now? Crit Care Clin 2020; 36: 23-40

10. Choe EA, Shin TG, Jo IJ, et al. The prevalence and clinical significance of low procalcitonin levels among patients with severe sepsis or septic shock in the emergency department. Shock 2016; 46: 37-43.

11. Brodska H, Malickova K, Adamkova V, Benakova H, Stastna MM, Zima T. Significantly higher procalcitonin levels could differentiate Gram-negative sepsis from Gram-positive and fungal sepsis. Clin Exp Med 2013; 13: 165-70.

12. Assicot M, Gendrel D, Carsin H, Raymond J, Guilbaud J, Bohuon C. High serum procalcitonin concentrations in patients with sepsis and infection. Lancet 1993; 341: 515-8.

13. Prkno A, Wacker C, Brunkhorst FM, Schlattmann P. Procalcitonin-guided therapy in intensive care unit patients with severe sepsis and septic shock-a systematic review and metaanalysis. Critical Care 2013; 17: R291.

14. Kalil AC, Metersky ML, Klompas M, et al. Management of adults with hospital-acquired and ventilator-associated pneumonia:2016 clinical practice guidelines by the Infectious Diseases Society of America and the American Thoracic Society. Clin Infect Dis 2016; 63: e61-e111.
15. Schuetz P, Albrich W, Mueller B. Procalcitonin for diagnosis of infection and guide to antibiotic decisions: past, present and future. BMC Med 2011; 9: 107.

16. de Jong E, van Oers JA, Beishuizen A, et al. Efficacy and safety of procalcitonin guidance in reducing the duration of antibiotic treatment in critically ill patients:a randomised, controlled, open-label trial. Lancet Infect Dis 2016; 16: 819-27. 